\title{
Cooperation and Competition During Development: Neonatal Lesioning of the Superior Cervical Ganglion Induces Cell Death of Trigeminal Neurons Innervating the Cerebral Blood Vessels but Prevents the Loss of Axon Collaterals from the Neurons That Survive
}

\author{
Timothy P. O'Connor and Derek van der Kooy \\ Neurobiology Research Group, Department of Anatomy, University of Toronto, Toronto, Ontario, Canada M5S 1A8
}

In the adult rodent trigeminal ganglion there is a period of postnatal cell death in the population of cells with axons innervating the middle cerebral artery ( $O$ 'Connor and van der Kooy, 1986b). The superior cervical ganglion (SCG) also has a projection to the middle cerebral artery (MCA; Mayberg et al., 1984; Cowen et al., 1986, 1987; present report). We hypothesized that the trigeminal ganglion cells innervating the MCA may be competing with the superior cervical projection for target area or for a target factor for survival, and thus the removal of the superior cervical projection at birth (sympathectomy) may promote the survival of some of the trigeminal-artery innervating cells that normally would die. Multiple fluorescent retrograde tracing was employed to analyze the postnatal development of the trigeminal projection to the MCA in sympathectomized and sibling control rats.

We found that the SCG projection to the MCA exhibits a period of postnatal cell death. The trigeminal ganglion projection exhibits axon degeneration as well as postnatal cell death. Postnatal day 0 (PO) lesioning of the SCG did not prevent cell death or axon loss in the trigeminal projection to the cerebral artery. In fact, increased cell death of the trigeminal-artery projecting neurons was observed in the lesioned animals when compared to nonlesioned sibling controls. By P55, we found that $80 \%$ of these trigeminal neurons had died in lesioned animals, compared with $50 \%$ in controls.

In both control and sympathectomized rats, close to $90 \%$ of the trigeminal neurons innervating the artery in the neonate can no longer be retrogradely labeled from the MCA by tracer applications at P25-90. Thus, although the presence of an intact SCG may protect some trigeminal-artery projecting neurons from cell death, it does not prevent axon retraction and does not permit a larger absolute number of trigeminal axons to innervate the arteries in the adult. Thus, separate mechanisms are responsible for the survival of perikarya versus the retraction of their axons from the MCA. Surprisingly, in the neonatally sympathectomized rats almost $20 \%$ of those trigeminal cells that maintained a projection to the MCA at P90 also had a projection to the forehead. In contrast, less than $3 \%$ of the artery innervating

Copyright C 1989 Society for Neuroscience 0270-6474/89/051490-12\$02.00/0 trigeminal cells in the $\mathrm{P} 90$ control rats had an axon collateral to the forehead.

These results suggest that competition between trigeminal and SCG cells may not be a factor in the normal postnatal loss of trigeminal cells that innervate the MCA. Indeed, in the absence of this sympathetic projection, trigeminal artery cells may find themselves in a more competitive environment. Thus, cooperation may occur between 2 neuronal pools innervating a common target, whereas competition may occur within each pool.

During the development of the vertebrate nervous system there is a period of naturally occurring neuronal cell death (Oppenheim, 1981; Berg, 1982; Cunningham, 1982; Hamburger and Oppenheim, 1982; Cowan et al., 1984). This cell death occurs in most areas of the nervous system; indeed, the lack of cell death appears to be the exception rather than the rule (Oppenheim, 1981; Berg, 1982; Cowan et al., 1984). Nithough cell death is widespread, the exact mechanisms underlying the phenomenon have not been elucidated. A popular hypothesis states that the nervous system produces an excess number of neurons necessary to innervate a particular target. Subsequently, these neurons must compete for a limited supply of target synaptic area or trophic substances released from the target in order to ensure their survival (Oppenheim, 1981). Thus, the size of the neuronal pool is matched to the target size. This has been termed the quantitative matching hypothesis (Hamburger and Oppenheim, 1982; Tanaka and Landmesser, 1986; Herrup and Sunter, 1987). This hypothesis may account for cell death within a single neuronal pool innervating a target as well as for the less frequently studied examples of cell death between neuronal pools innervating common targets. These 2 different types of competition within the muscle innervating motoneuron system have been termed homospecific (within a motoneuron pool) and heterospecific (between motoneuron pools) (Oppenheim, 1981, p. 103). We have adopted these terms to describe other examples of competition between neuronal pools and within a neuronal pool. There are several examples of heterospecific competition in the CNS that are consistent with the quantitative matching hypothesis (Woodward et al., 1974; Crepel et al., 1976; Rhoades and Dellacroce, 1980; Caminiti and Innocenti, 1981; Crepel, 1982; Lund et al., 1984). For example, in the adult rat cerebellum each Purkinje cell receives input from only 1 inferior olive climbing fiber. However, in the neonate, many individual Purkinje cells are observed to have inputs from 2 or more climb- 
ing libers. The loss of these additional climbing fiber inputs to Purkinje cells occurs in the early postnatal period and appears to be due in part to competition with granule cell terminals at the Purkinje cell target (Crepel, 1982). In animals with few or no granule cells (weaver mutants or animals irradiated during development), these multiple climbing fiber inputs persist (Crepel et al., 1976; ( repel, 1982). Thus, 2 spatially discrete neuronal pools (inferior olive and granule cell layers) appear to compete at a common target (the Purkinje cell), possibly for a released trophic factor (Crepel, 1982). Other similar examples of heterospecific competition include the thalamocortical and callosal innervation of the visual cortex (Rhoades and Dellacroce, 1980; Lund et al. 1984) and the ipsilateral corticocortical and callosal projections to somatosensory cortex (Caminiti and Innocenti, 1981). In most of these experiments, however, investigators reported on process elimination rather than cell death. The present experiment differs somewhat from the aforementioned studies in the ( $N S$ in that we studied heterospecific competition between 2 distinct and separate peripheral projections (the sensory and sympathetic autonomic projections) innervating a common target (the cerebral blood vessels). We tested the hetcrospecific competition hypothesis by eliminating the putative competitive interactions between these 2 separate neuronal pools and then asked whether this promotes the survival of some neurons that normally would die. We report that neuronal cooperation as well as neuronal competition may be important in the consolidation and survival of a neuronal projection.

The rat trigeminal ganglion is the major sensory ganglion projecting to the dura and cerebral blood vessels (O'Connor and van der Kooy, 1986a: Andres et al., 1987: Saito el al., 1987). In the mouse the ganglion is first visible at embryonic day 9 (E9). and by E10 fibers have begun to extend from the ganglion, some contacting their peripheral fields as early as E11-12 (Lumsden and Davies, 1983). At this time the number of neurons in the ganglia is still increasing. reaching a maximum at E 13 (Davies and Lumsden. 1984). This ganglion then goes through a period of prenatal cell death between E 13 and postnatal day $4(\mathrm{P} 4)$, with approximately $50 \%$ of the trigeminal neurons dying (Davies and Lumsden, 1984). Development of the ganglion in the rat occurs later embryonically than in the mouse. with rat trigeminal cells born predominantly on E 3 and E14 (Forbes and Welt, 1981) and first making contact with peripheral targets by E14-15 (Erzurumlu and Killackey, 1983). Rat trigeminal neurons probably go through a period of embryonic cell death similar to that in the mouse. In addition. between P5 and P90 in the rat, more than $50 \%$ of the neurons in the urigeminal ganglion specifically projecting to the middle cerebral artery (MCA) die (O'Connor and van der Kooy, 1986b; present report). It is not known whether this specific pool of trigeminal neurons is also subject to prenatal cell death.

The superior cervical ganglion (SCG) also innervates the MCA (Mayberg et al. 1984; Cowen et al., 1986, 1987; present report). In the rat. cells in this ganglion first extend axons as early as E12 (a ume at which only a small number of the ganglion cells have emerged from the mitotic cycle). Some axons reach distant sympathetic targets (such as the orbit) as carly as El5 (Rubin, 1985). Cells in the ganglion continue to divide and send out axons up to P4 (Hendry, 1977: Rubin, 1985). During the first few postnatal weeks, the sympathetic innervation along the vasculature continues to develop physiologically and anatomically (Ljung and Stage, 1975; Cowen and Burnstock. 1986). From P6 10 P28. $30 \%$ of the total population of SCG cells die (Hendry and Campbell. 1976). This cell death can be prevented by administration of nerve growth factor (NGF: Hendry and Campbell, 1976)

In both the neonatal and the adult rat, lesioning the SC ; results in an increase in the amount of NGF available at sympathetic target tissues (Ebendal et al., 1980: Korshing and Thoenen, 1985), which causes a subsequent increase in synthesis and transport of substance $P$ and calcitonin gene related peptide from the trigeminal ganglion to the iris and cercbral blood vessels (Kessler et al.. 1983: Kessler. 1985: Schon ct al. 1985). This increased trigeminal neuropeptide synthesis in sympathectomized rats can be reproduced in control rats with ad ministration of NGF or blocked with the administration of NGF antiserum at the target tissue in lesioned rats (Kessler et al.. 1983: Kessler. 1985). It has therefore been proposed that trigeminal and sympathetic neurons compete for a constant (Shelton and Reichardt. 1986) source of NGF at common peripheral targets (Kessler c1 al., 1983: Kessler, 1985). Thus, just as parallel fibers compete with climbing fibers at the Purkinje cell (Crepel et al.. 1976: Crepel, 1982), thalamocortical projections compete with callosal projections in visual cortex (Rhoades and Delacroce. 1980; Lund et al., 1984) and callosal projections compete with ipsilateral corticocortical projections in somatosensory cortex (Caminiti and Innocenti. 1981), we hypothesized that heterospecific competition between 2 anatomically separate, peripheral projections that innervate the same target may be important in their development and/or differentiation.

In the present report we asked 2 questions. First, does the SCG projection to the MCA exhibit a period of postnatal cell death similar to that of the trigeminal projection? We hypothesized that if sympathetic cells were competing with trigeminal cells for survival, then the sympathetic projection may exhibit a period of postnatal cell death similar to that observed in the trigeminal projection. Second, will lesioning the sympathetic projection in newborns prevent some of the naturally occurring cell death observed postnatally in the trigeminal projection to the MCA?

\section{Materials and Methods}

The offspring of pregnant albino Charles River rats were used for all experiments. Rat pups were recorded as $\mathrm{PO}$ on the day of birth, and each litter was divided into 5 groups: 2 SCG-lesioned and 3 SC ( $\mathrm{j}-$ nonlesioned control.

SCG lesions. At P0 (usually within 8 hr of birth), 2 of the 5 groups of rat pups were anesthetized using cold temperatures. These 2 groups then had their right SCG surgically removed. Briefly. a ventral midline incision was made in the neck and the right carotid artery was dissected from the surrounding muscle and connective tissue. The external and internal branches of the carotid artery were located as they bifurcate from the common carotid artery. The SCG is nestled dorsally in the bifurcation. Using a Zeiss operating microscope, the right $S C \mathrm{C}$ was dissected free of the carotid sheath. isolated, and removed using fine forceps. The animals were then sutured and rewarmed until they had recovered.

Maturation of the SC $i$ projection to the MC.1. At P3. rat pups from one of the non-SCG-lesioned groups were anesthetized as above. From a lateral parietotemporal approach, the right MCA was isolated just ventral to the rhinal sulcus using a Zeiss operating microscope. The dura was cut and reflected away from the artery. Incisions were made in the pia-arachnoid on both sides of the artery, and a small triangular piece of parafilm (approximately $1 \times 4 \mathrm{~mm}$ ) was placed under the artery in order to limit tracer spread. A viscous $(>10 \%)$ solution of Fast Bluc (FB) was applied directly to the artery and left for 5 min to allow it to adhere. The artery was then covered by 2 or 3 layers of gel foam at the site of application, and all this was covered by another strip of parafilm. Animals were sutured and allowed to survive to either P5 or P90. In preliminary experiments FB appeared to give brighter retrograde la- 


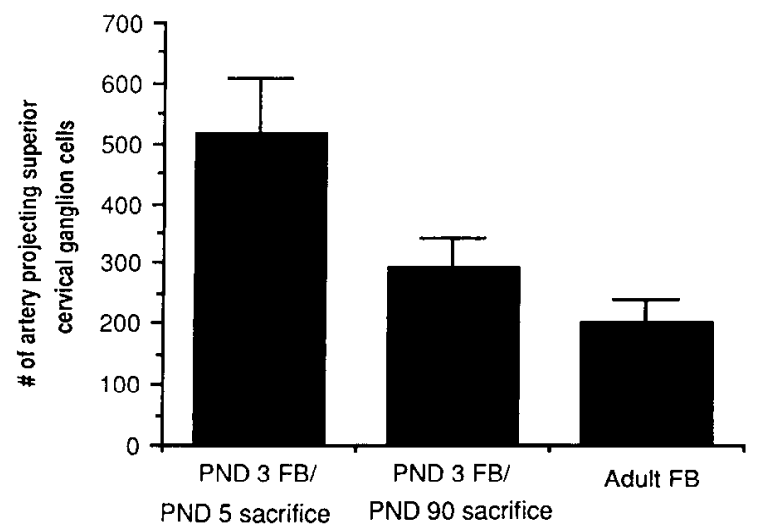

Figure 1. Superior cervical ganglion cells that innervate the MCA die postnatally. After a neonatal FB application to the MCA of nonlesioned rats, the number of retrogradely labeled FB cells observed in the SCG was significantly greater at P5 than at P90. The not significantly different numbers observed at $\mathrm{P} 90$ after neonatal or adult application indicates that cell death rather than axon retraction is occurring. Data represent means \pm SEM for each group. The number of rats in each group is: P5, $n=7 ; \mathrm{P} 90, n=7 ;$ and adult operated, $n=6$.

beling of the SCG projection than did True Blue (TB). However, FB and TB applications produced similar numbers of retrogradely labeled neurons in the trigeminal ganglion. In order to be consistent with past studies we used TB in the experiments described below to analyze trigeminal projections.

At the time of death the animals were deeply anesthetized with sodium pentobarbitol and transcardially perfused with $10-100 \mathrm{ml}$ of $0.9 \%$ saline followed by $50-400 \mathrm{ml}$ of $10 \%$ formalin (volumes increased with age). Brains as well as trigeminal ganglia and SCG were removed, stored in $20 \%$ sucrose, and then sectioned at $32 \mu \mathrm{m}$ (for trigeminal) and $24 \mu \mathrm{m}$ (SCG) in a cryostat at $-14^{\circ} \mathrm{C}$. All sections of the trigeminal ganglia ipsilateral to the application were collected in $0.1 \mathrm{M}$ phosphate buffer and mounted on gelatin-coated slides. Brains were also sectioncd in order to examine the spread of $F B$ from the artery to the cortex. The slides were coverslipped with glycerol and water $(1: 1)$ and examined under a Leitz epifluorescent microscope at a wavelength of $360 \mathrm{~nm}$. Labeled cells containing FB were counted throughout the ganglia. Applications of FB were also carried out on previously unmanipulated $\mathrm{P} 90$ (or older) rats. Briefly, the animals were anesthetized with sodium pentobarbitol (Somnotol, $65 \mathrm{mg} / \mathrm{kg}$ ) and had FB applied to the MCA in the same manner as the pups. Four days later the animals were killed, perfused, and the ganglia were processed as described above.

Maturation of the trigeminal perikarya projecting to the MCA in lesioned and nonlesioned animals. At P3 the pups in one group of the lesioned animals and one group of the nonlesioned controls had TB applied to their right MCA exactly as described above for the FB applications. Only lesioned animals exhibiting ptosis, the presence of which confirmed an SCG lesion, were used in the study. The animals were allowed to survive to P5, P25, P55, or P90. Labeled cells containing TB were counted in the trigeminal ganglia. The right carotid artery was also removed from the lesioned animals at sacrifice and sectioned. These sections were first examined under an epifluorescent microscope for retrogradely labeled cells and then Nissl stained and observed under a Nikon light microscope to confirm the presence or absence of an SCG.

Retraction of trigeminal axons innervating the $M C A$. The remaining lesion group and its sibling control group did not have a tracer application as neonates but were allowed to survive, as above, to P5, P25, P55, or P90. However, 2-5 d prior to death these animals had TB applied to their right MCA. This allowed determination of the number of trigeminal cells actually innervating the MCA just prior to death, whereas the experiments described above indicate the number of trigeminal cells and SCG cells still present at the time of death that projected to the MCA at P3. The applications of TB were exactly as described for the FB applications. A second operation was performed just prior to death in some of the animal. Animals were anesthetized either with ether or with cold temperatures (at P5), and, using a $50 \mu$ l Hamilton syringe, $3-15 \mu$ l of $2 \%$ Diamidino Yellow (DY; volumes increased with the age of the animal) were injected subcutaneously into the right fo- rehead skin. After 16-24 hr of survival, the animals were killed and processed as described above. Labeled cells containing TB only or both TB and DY were counted in the ipsilateral trigeminal ganglia. Again, the lesioned animals were checked prior to surgery (for ptosis) and after death to confirm the SCG lesion.

All labeled cell counts in all experiments were corrected by the method of Abercrombie (1946) applied to split cells, unless cell numbers were so low that split cells were easily observed. TB- and FB-labeled cells can be distinguished by the fine blue fluorescence throughout the cytoplasm of the cell, whereas DY-labeled cells can be distinguished by a white-yellow fluorescence of the nucleus. All cells exhibiting detectable blue cytoplasmic fluorescence or yellow nuclear fluorescence were counted as labeled.

To test whether SCG lesions affected the number of trigeminal perikarya projecting to the forehead, we allowed some additional lesioned and nonlesioned sibling controls to mature $(>$ P90). The adult animals were anesthetized, and the right frontal branch of the ophthalmic nerve was dissected free of tissue just distal to the supraorbital foramen and cut. The transected nerve was laid on a piece of parafilm, and TB-soaked gel foam was applied directly to the proximal end. This was covered by 2 layers of dry gel foam and an outer layer of parafiln. The animals were then sutured and allowed to recover. After 4-5 d animals were killed and processed as above. All TB-labeled cells in the trigeminal ganglion ipsilateral to the SCG lesion were counted.

\section{Results}

Maturation of the SCG projection to the $M C A$

Cell death, but no additional axon retraction, is seen postnatally in the SCG projection to the MCA (Fig. 1). The number of FB retrogradely labeled SCG cells observed in P90 animals after tracer application at $\mathrm{P} 3$ is $45 \%$ less than that observed in P5 pups after tracer application at P3. This significant change $(t(d f$ $=12)=2.6, p<0.05$ ) reflects postnatal cell death in the SCG artery projecting population. The number of retrogradely labeled SCG cells that survived to P90 after a P3 application does not differ significantly $(t(d f=11)=1.5, p>0.05)$ from the number of labeled cells seen to project to the MCA after tracer application in the adult, suggesting that in the adult there is no additional axonal loss in the surviving SCG population.

\section{Maturation of the trigeminal perikarya projecting to the MCA in lesioned and nonlesioned animals}

As previously reported (O'Connor and van der Kooy, 1986b), the number of trigeminal ganglion cells innervating the MCA decreases postnatally in the nonlesioned controls (Fig. $2 A$ ). All of this cell death occurs in the first 25 postnatal days.

In animals with ipsilateral SCG lesions, the number of trigeminal ganglion cells innervating the $\mathrm{MCA}$ also decreases postnatally (Fig. $2 A$ ). Cells retrogradely labeled in the neonate are lost at equivalent rates in the 2 groups until P25, but by P55 the ganglia of the lesioned group retain significantly fewer labeled neurons than do the ganglia of the control group ( $t(d f=$ $17)=2.3, p<0.05$ ). There is no further loss of trigeminal cells after P55 in either lesioned or control animals. Sampling the number of cells at P5, P25, P55, and P90 describes only artificial boundaries for the periods of degeneration; rates of cell death may not be linear between the sampling points. A typical TB application to the MCA at P3 and the resulting retrograde trigeminal labeling are shown in Figures 3 and 4, respectively. Cells labeled in the neonate are smaller, more numerous, and more densely packed (Fig. $4 A$ ) than are those observed in the adult (Fig. 4B).

\section{Retraction of trigeminal axons innervating the $M C A$}

In order to differentiate 2 regressive events (cell death versus degeneration of an artery axon without perikaryal death) in the 
trigeminal-vascular projection, we applied TB to the MCA's of neonatally lesioned and control animals just prior to death. These experiments show the number of trigeminal cells that actually have an axon innervating the MCA just prior to death. It is interesting to note that in the control animals the number of P90 labeled trigeminal cells is much larger after a P3 application (Fig. 2A) than it is after a P86 application (Fig. 2B). This suggests that many of the surviving MCA innervating trigeminal cells lose their axon from the MCA by P86. These results show that axon retraction plays a larger role in the postnatal development of the trigeminal-MCA projection in control animals than was previously thought (O'Connor and van der Kooy, 1986b).

Figure $2 B$ shows that in both neonatally sympathectomized and nonlesioned animals the majority of trigeminal axons innervating the MCA are lost postnatally. Virtually all of this degeneration of trigeminal axons innervating the MCA occurs between P5 and P25. At P25 there is no significant difference between the number of artery innervating trigeminal cells in the control and lesioned animals $(t(d f=14)=1.7, p>0.05)$. Thus, lesioning the SCG does not alter the rate of axon degeneration or the final number of cells innervating the MCA. In the adult, the MCA of lesioned animals is able to support the full complement of trigeminal cells that normally innervate the MCA in control animals.

In these experiments we have assumed that applications at various postnatal ages sample virtually all of the trigeminal axons sensory to the MCA and that artery size at the time of application is not a factor in these results. Several points support this assumption. First, only the amount of TB necessary to cover the MCA was applied to an animal; thus, less TB was applied to a P3 animal than to a P86 animal. Second, the size of the artery increased between $\mathrm{P} 25$ and P90 (and therefore the size of the application was increased), yet the same number of trigeminal cells were retrogradely labeled. Third, trigeminal sensory axons run longitudinally along the MCA (Hanko et al., 1985; Wanaka et al., 1986); thus, a TB application to the proximal MCA should adequately expose TB to all the trigeminal axons running to more distal areas along the MCA.

\section{Trigeminal cells with axon collaterals to the MCA and forehead}

Some of the animals studied in the section immediately above for trigeminal axon retraction also received an injection of DY in the forehead just prior to death in order to study trigeminal axon collateralization. An analysis of trigeminal ganglion cells retrogradely double-labeled from a TB adult application to the MCA and a DY adult injection in the forehead (Fig. 5) shows that at P90 very few cells innervate both the MCA and the forehead in nonlesioned animals. At P5 approximately $15 \%$ of the MCA projecting cells also project to the forehead. Thus, between P5 and P90 in nonlesioned animals, the collateralized cells either retract their axons from the MCA or from the forehead, or they die. However, we have previously demonstrated that many of the cells that had axons to both the forehead and MCA al P5 do survive to P90 (O'Connor and van der Kooy, 1986b). Moreover, there is little axonal loss of ganglion cells projecting to the forehead (O'Connor and van der Kooy, 1986b). Thus, we suggest that in nonlesioned animals many of these collateralized cells retract their axon from the MCA, producing only the few cells observed innervating both targets at P90 (Fig. 5).
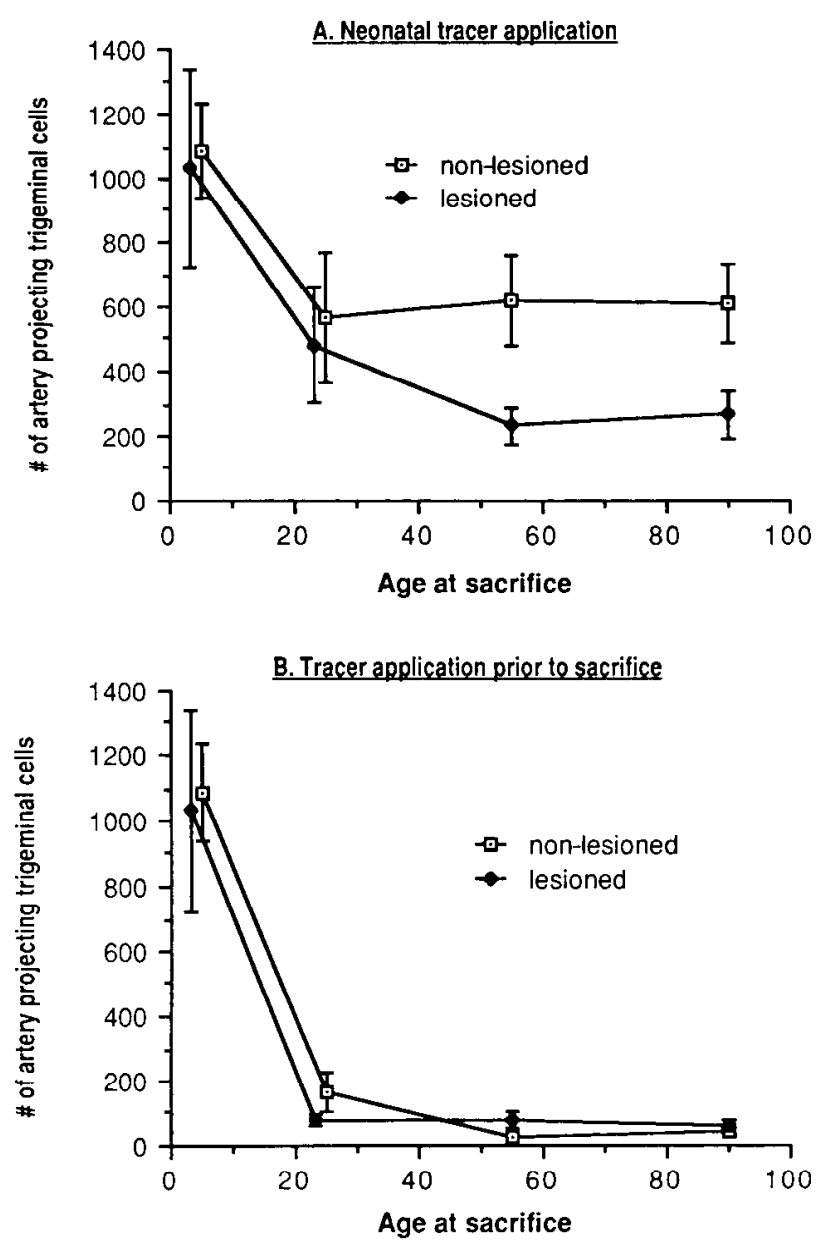

Figure 2. A, Trigeminal cells innervating the MCA in nonlesioned and especially SCG lesioned animals die postnatally. Lesioned animals had their SCG removed at P0. After a TB application to the MCA of both groups at P3, the number of retrogradely labeled TB cells observed at a subsequent postnatal survival time decreases with age. Animals with SCG lesions showed an extended period of cell death from P25 to P55 that was not observed in nonlesioned animals. Data represent means \pm SEM for each group. The number of rats in each group is: nonlesioned, P5, $n=9 ; \mathrm{P} 25, n=8 ; \mathrm{P} 55, n=11$; and P90, $n=8$; lesioned P5, $n=$ 5; P25, $n=6$; P55, $n=8$; and P90, $n=5$. B. Approximately $90 \%$ of trigeminal axons innervating the neonatal MCA retract from the MCA by $\mathrm{P} 25$ in both lesioned and nonlesioned animals. TB was applied to the MCA 2-4 d prior to sacrifice. These results reflect both cell death (Fig. $2 A$ ) plus axon retraction by surviving cells. Thus, at P25, 50\% of the original population have died and a further $45 \%$ have retracted their axons. Data represent means \pm SEM for each group. The number of rats in each group is: lesioned, $\mathrm{P} 5, n=5 ; \mathrm{P} 25, n=8 ; \mathrm{P} 55, n=8 ; \mathrm{P} 90$, $n=5$; nonlesioned, P5, $n=9 ; \mathrm{P} 25, n=7 ; \mathrm{P} 55, n=8$, and P90, $n=8$.

In contrast to the control animals, the neonatally lesioned animals have a significantly $(t(d f=9)=3.1, p<0.05)$ larger percentage of adult (P90) trigeminal-MCA projecting cells with axon collaterals to the forehead (Fig. 5). Thus, the trigeminal artery projecting cells that survive specifically in the lesioned animals are more likely to maintain an axon collateral to 2 different targets postnatally. Figure 6 shows a typical doublelabeled trigeminal cell in a lesioned animal after an adult TB application to the MCA and a DY injection in the forehead.

A final experiment investigated the effects of neonatal SCG lesions on the number of trigeminal ganglion cells retrogradely labeled from an adult TB application to the frontal branch of 
Figure 3. A coronal section of a rat brain showing the area of TB application to the right MCA at P3. The spread of TB was confined to the areas immediately surrounding the artery (arrows).

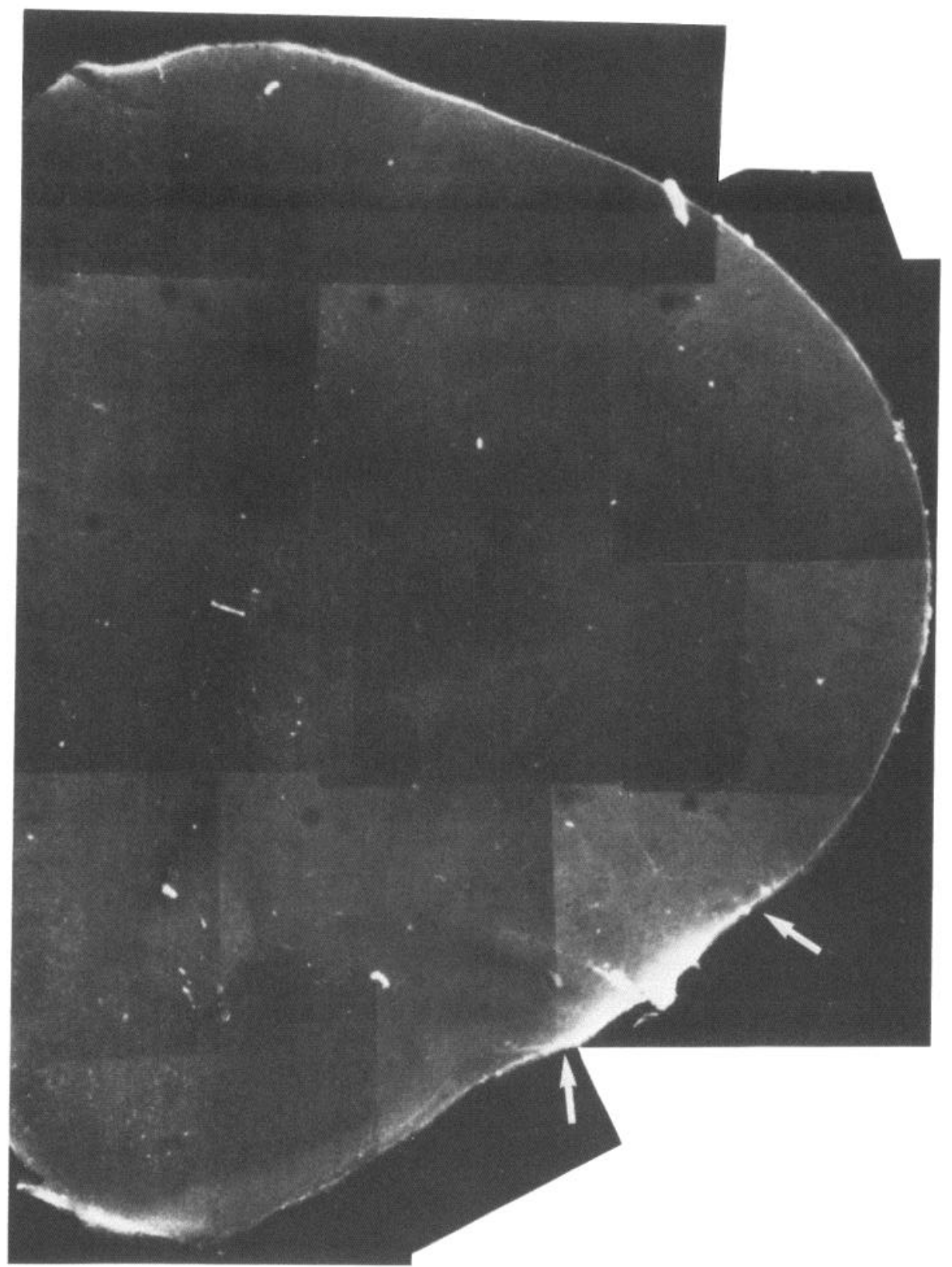

In nonlesioned P5 animals approximately $15 \%$ of the cells that project to the MCA also project to the forehead. By P55, after the cell death and retraction period, close to $25 \%$ of the surviving trigeminal cells that had projected to the MCA at P5 have an axon projecting to the forehead (O'Connor and van der Kooy, 1986b). Thus, the percentage of surviving trigeminal cells with axon collaterals actually increases as neurons are dying, suggesting that between P5 and P90 these cells with axon collaterals to 2 targets may have a selective advantage for survival. However, very few trigeminal neurons that project to the MCA at P55 or P90 also project to the forehead (O'Connor and van der Kooy, 1986; present report). Furthermore, there is very little cell death or axon retraction specifically within the trigeminal population projecting to the forehead (O'Connor and van der Kooy, 1986b). Therefore, trigeminal neurons that had collaterals to both the MCA and forehead at P5 (and then preferentially survive to P55 or P90) must retract their artery innervating 

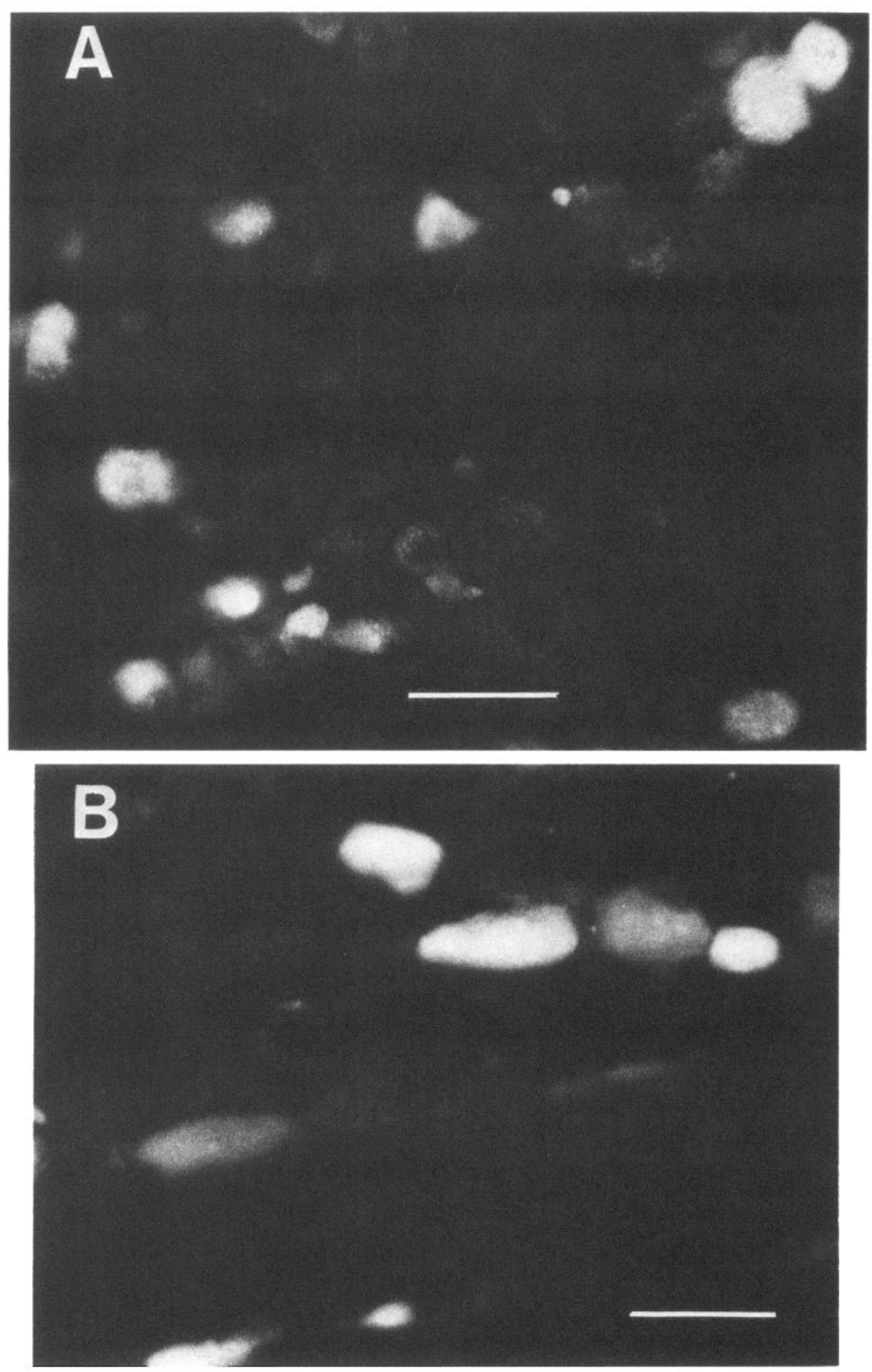

Figure 4. Retrogradely labeled cells in the trigeminal ganglia of SCG lesioned animals after a TB application to the MCA. $A$, Animal had a TB application at P3 and was sacrificed at P5. Cells in the ganglia are small, numerous, and densely packed. TB labeled cells have a diffuse blue cytoplasmic labeling. $B$, Trigeminal cells in a $\mathrm{P90}$ rat. TB was applied to the MCA at P3, and the rat was sacrificed at P90. Cells in the ganglia are larger and less densely packed. Bar, $50 \mu \mathrm{m}$ for both $A$ and $B$. axon during development to be left with only an axon innervating the forehead in the adult.

A second projection to the cerebral arteries, the SCG projection, also exhibits a period of postnatal cell death. The amount of cell death in this projection is greater than the $30 \%$ postnatal reduction in the total number of cells observed throughout the ganglion (Hendry and Campbell, 1976).
The primary purpose of these experiments was to test the hypothesis that competition between 2 distinct projections to a common target plays a regulatory role in determining the number of neurons that ultimately project to the target. This has been termed heterospecific competition (Oppenheim, 1981, pg. 103). Specifically, we asked whether the autonomic SCG projection to the MCA competes with the trigeminal projection for 


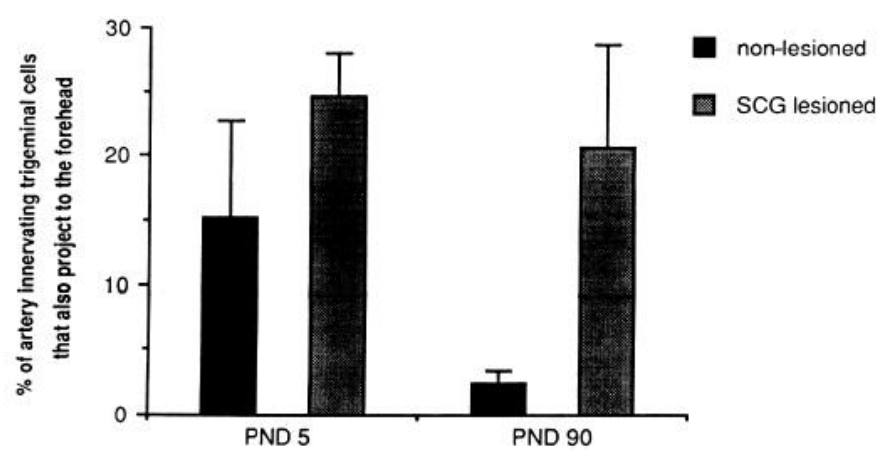

Figure 5. The percentage of trigeminal cells that have an axon innervating both the MCA and the forehead (expressed as a proportion of the total number of MCA projecting cells) at the time of sacrifice. In nonlesioned animals the percentage of cells with axons to the MCA and forehead decreases postnatally. At P90 very few artery innervating cells also project to the forehead. In the lesioned animals, however, the percentage of cells with axon collaterals to the forehead and MCA remains constant over the postnatal period. Thus, lesioning the SCG allows trigeminal artery cells to maintain distant axon collaterals to targets they would normally retract from. Data represent means \pm SEM for each group of rats. The number of rats in each group is: lesioned, P5, $n=8$; P90, $n=4$, nonlesioned, P5, $n=8$; P90, $n=7$.

target area or for a target-derived survival factor and thus regulates the cell death observed in the trigeminal-MCA projection (O'Connor and van der Kooy, 1986b; present report). The principal finding from these experiments is that removal of the SCG projection to the MCA at birth does not prevent the cell death observed in the trigeminal projection. On the contrary, removal of the SCG resulted in an increase in the postnatal loss of trigeminal cells that had innervated the MCA at P5. The SCG lesions did not affect the number of trigeminal cells innervating the forehead. However, 2 other interesting findings emerged from the data. First, although fewer of the trigeminal neurons that innervated the MCA at P5 survive to P90 in the lesioned

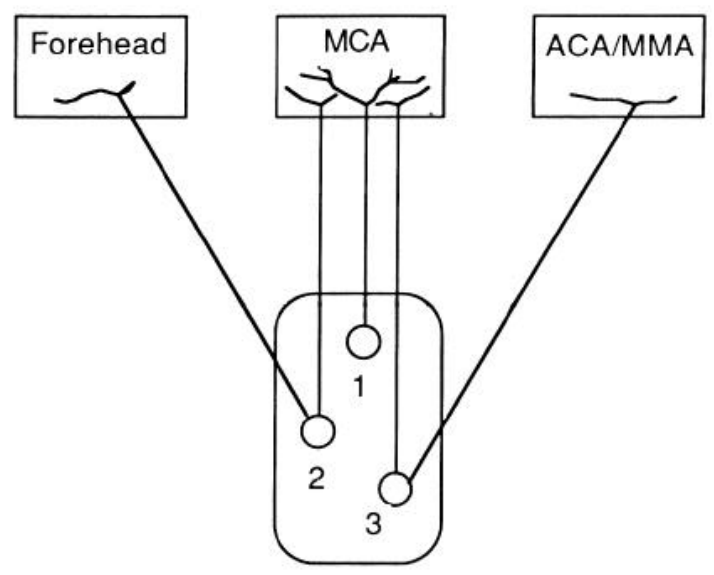

Figure 7. A summary diagram of the 3 groups of trigeminal neurons that innervate the MCA in the neonate. Neurons are grouped by their collateral projections. Group 1 projects exclusively to the MCA, whereas each neuron in group 2 and 3 also has a collateral projection to the forehead and another intracranial artery, respectively. During normal development there is considerable perikaryal death, especially among group 1 neurons. Group 2 neurons do not die but simply retract their MCA axons. After neonatal SCG lesioning, the majority of neurons in both groups 1 and 3 die, but the neurons of group 2 retain both their forehead and MCA axon collaterals. $M C A$, middle cerebral artery; $A C A$, anterior cerebral artery; $M M A$, middle meningeal artery.

rats, the final number of cells that projected to the MCA in an adult (P90) is the same in lesioned and nonlesioned animals (due to axon retraction by the surviving cells). Second, many of the adult trigeminal cells that project to the MCA in lesioned animals are able to maintain a projection to another extracranial target (the forehead). These collateralized trigeminal cells are very rarely observed in nonlesioned adult animals. Although SCG lesions do not rescue trigeminal cells from death (in fact, SCG lesions induce more death in the trigeminal-MCA projec-
Figure 6. Retrogradely labeled cells in the trigeminal ganglion of an SCG lesioned animal after a TB application to the MCA and DY injection into the forehead. The TB and DY applications were performed on an adult that had been neonatally lesioned. TB only ( $a r$ rowheads), DY only (arrow), and a double-labeled cell (open arrow) can be observed. Bar, $50 \mu \mathrm{m}$.

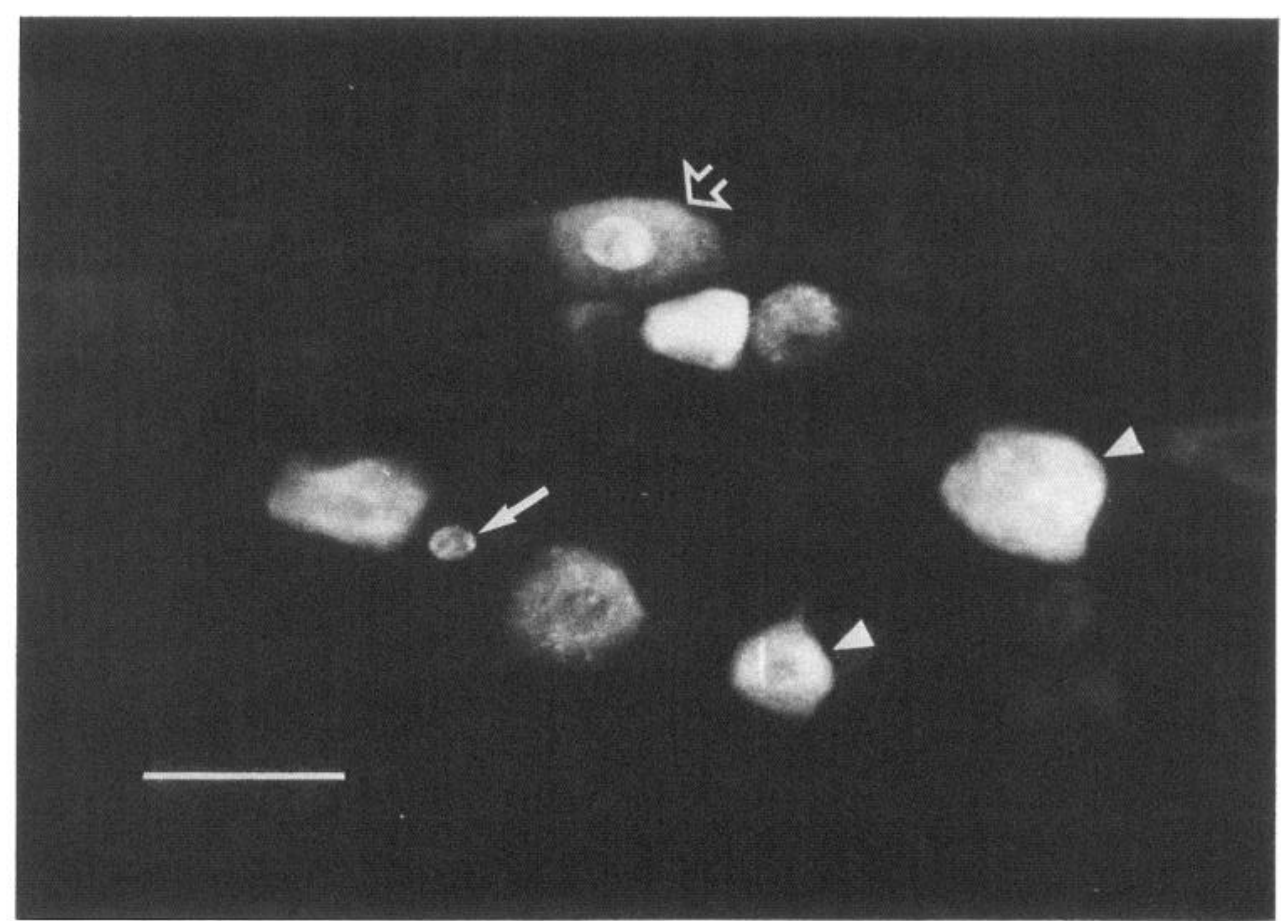


tion), the cells that do survive are able to maintain supernumerary axons. In fact, the occurrence of collateral axons may be necessary for their survival.

\section{The death of artery innervating trigeminal perikarya: a model}

We propose that the neurons that initially project to the MCA in the neonate can be divided into 3 groups based on their axon collateral projections (Fig. 7). First, there is a group of trigeminal cells that project exclusively to the MCA; that is, these neurons do not have collateral projections to cither extracranial (forehead) or other intracranial (arterial) targets. Second, there is a population of neurons that each have collaterals to extracranial sites as well as to the MCA (O'Connor and van der Kooy, $1986 \mathrm{~b}$ ). A third group of trigeminal perikarya each have axon collaterals to the MCA and to other intracranial arteries (such as the anterior cerebral and middle meningeal; O'Connor and van der Kooy, 1986a). Under normal circumstances neurons that innervate the MCA and another extracranial target (e.g., the forehead) preferentially survive the cell death period but retract their axon collateral from the MCA. We base this on the following findings: (1) Approximately $15 \%$ of the trigeminalMCA neurons also project to the forehead at P5; (2) very few cells with a forehead projection die or retract their axons postnatally from the forehead target (O'Connor and van der Kooy, $1986 \mathrm{~b}$ ); and (3) virtually none of the forehead projecting cells also project to the MCA in the adult (O'Connor and van der Kooy, 1986a). Thus, the group of neurons that have collaterals to the forehead and MCA in the neonate preferentially survive the postnatal cell death period but retract their MCA axon (O'Connor and van der Kooy, 1986b). This suggests that the forehead axonal projections of these trigeminal cells may determine the survival of their perikarya, and consequently that competition by the MCA axon collaterals is not relevant to their perikaryal survival. However, other neurons that project exclusively to the MCA or have collaterals to other intracranial arteries must compete intracranially to ensure the survival of their perikarya.

We have suggested previously that neurons with a wide field of innervation along the MCA or neurons with collateral projections to other intracranial arteries as well as to the MCA have an advantage for perikaryal survival (O'Connor and van der Kooy, 1986b). These neurons obtain enough factor for their survival. We propose that under normal circumstances most of the surviving perikarya with axonal projections to the MCA and another intracranial artery retract the MCA innervating collateral postnatally. However, this does not occur in all trigeminal neurons that innervate the MCA And another intracranial artery, as a significant number of trigeminal neurons in the adult still project to both arterics (O'Connor and van der Kooy, 1986a). In summary, we propose that neurons with a collateral projection to the forehead or a wide field of innervation to the arteries preferentially survive the cell death period. However, all of these cells with axon collaterals to the forehead and MCA, and the majority of cells with axon collaterals to other intracranial arteries and the MCA, retract their collaterals from the MCA. We suggest that perikaryal survival and axon retraction are separable processes. In normal rats, individual trigeminal perikarya with an axon collateral to another intracranial artery or to the forehead may survive the perikaryal cell death period but retract their MCA axon. On the other hand, many trigeminal perikarya that project only to the MCA in the neonate will die in the postnatal period, but those that survive will retain their axon plexus at the MCA. This separation of cell death and axon retraction is similar to that observed in the motoneuron system. The innervation of a given area of muscle decreases, first. during the period of motoneuron cell death (Bennet and Lavidis, 1982), and, second, during elimination of polyncuronal innervation (Brown and Booth, 1983).

We propose that when the SCG is lesioned the cerebral blood vessel environment becomes survival factor deficient (possibly because of the arrest of the vessels' development in an immature statc, as discussed below). This deficiency occurs along other intracranial arteries as well as the MCA. With less survival factor, neurons that rely solely on cerebral artery targets for survival will be selected against, because the field of innervation necessary to receive an adequate amount of survival factor would be unrealistically large. Thus, most or all of the neurons that project exclusively to the MCA, including those that under normal conditions competed to receive enough factor to survive, would be the first neurons to die in lesioned animals. Second, normally surviving perikarya that had collaterals to other intracranial arterial targets as well as to the MCA would also die owing to the poor survival factor environment at all the other intracranial arteries.

The SCG lesion effect on cell death is protracted, so that the increased cell death in the lesioned animals occurs after the normal period of cell death has been completed. The cells demonstrating this delayed cell death in the lesioned animals may be the trigeminal cells that have axon collateral projections to other intracranial arteries. By P25 many of the cells with a single collateral to the MCA may have retracted it. but still project to other arteries. Under normal conditions these other intracranial projections would permit the survival of the cells. In the $\mathrm{SC} G$ lesioned rats these neurons may survive the normal period of cell dcath and MCA axon retraction by means of their other intracranial collaterals; however, they eventually die because of the survival factor poor environment at all the intracranial arteries. Indeed, a prediction of our model is that lesioned rats will have a lower percentage of trigeminal cells with projections to 2 intracranial arteries as adults than will control rats.

It is important to note that although more trigeminal ncurons that projected to the MCA at P5 had died by P90 in the lesioned compared to the control animals, both the lesioned and nonlesioned animals had the same number of trigeminal cells projecting to the MCA at P90. Many of the surviving trigeminal perikarya in the nonlesioned animals still retracted their axons from the MCA. Thus, it appears that maintenance of axonal projections and cell death are regulated separately. This dissociation of cell death and axonal projections has also been shown by Sohal et al. (1986) in chimeric animals. They found that the larger host duck eye muscles did not increase the survival of neurons in the transplanted quail trochlear nucleus but did promote the maintenance of almost twice as many motor end plates per neuron. Perhaps the final number of axons that innervate the cerebral arteries is regulated solely by the amount of arterial target space available. After neurons have competed for survival, there may be a second competition for target space (or a second factor) that determines the maintenance of an axon at the MCA. Thus, in lesioned animals we suggest that with the loss of the majority of trigeminal perikarya with only intracranial projections, those trigeminal-MCA cells that survive owing to their forehead axon collaterals may be left with MCA axon collaterals that come into contact with enough artery area (or a second factor) to persist beyond the normal retraction period. 
That is, retention of an MC $\Lambda$ axon collateral may be a consequence of the increased loss of cells that normally innervate the artery exclusively rather than a mechanism that directly increases the survival of the neurons that also have forehead projections.

In summary, during normal development individual trigeminal perikarya with widespread intracranial arterial innervation (population 3 in Fig. 7) or with a collateral to the forehead (population 2 in Fig. 7) are the most likely to survive the period of postnatal cell death. In animals with SCG lesions, a greater number of neurons that project only to intracranial targets die, yet the neurons with extracranial axon collaterals to the forehead again show preferential survival. In normal animals these forehead projecting cells retract their axon collaterals from the MCA. With the greater loss of neurons that project exclusively to intracranial targets in SCG lesioned animals, some of the forehead projecting neurons are now able to maintain arterial axon collaterals. Thus, the SCG lesions select the trigeminal population with widespread intracranial projections for death and select the trigeminal population with forehead and MCA collaterals not to retract their MCA axons.

This model incorporates only those projections that are currently characterized. The organization of trigeminal projections may be more complex. For example, some trigeminal cells may project to all 3 targets, and cells projecting to the MCA or alternate arterial targets may also have collaterals to other extracranial targets. However, we feel that Figure 7 is the most parsimonious description of the anatomy underlying the development of the known trigeminal projections.

\section{Competition and trophic molecules in trigeminal cell death}

The most popular explanation for naturally occurring cell death in the peripheral nervous system suggests that there is initially an overproduction of neurons and that target tissues regulate neuronal survival by limiting the availability of synaptic space or survival factors (Oppenheim, 1981; Cunningham, 1982; Hamburger and Oppenheim, 1982; Cowan et al., 1984). This hypothesis is supported by experiments demonstrating increased neuronal cell death when targets fail to develop because of genetic mutations (Lanser et al., 1986) or are removed experimentally (Hamburger and Levi-Montacini, 1949; Cowan and Wenger, 1967; Pilar and Landmesser, 1976; Hamburger and Yip, 1984) and by experiments showing decreased cell death after the addition of more target tissue (Hollyday and Hamburger, 1976) or the reduction of the number of competing neurons (Lance-Jones and Landmesser, 1980; Pilar et al., 1980). Accumulating evidence suggests that target-released trophic molecules are the limiting factor in the survival of sensory and sympathetic projections (Hendry and Camphell, 1976; Hamburger and Yip, 1984; Thoenen and Edgar, 1985; Davies et al., 1986).

The best known trophic factor promoting survival of sensory and sympathetic neurons during the period of naturally occurring cell death is NGF (Hendry and Campbell, 1976; Hamburger et al., 1981; Oppenheim, 1981; Berg, 1982; Thoenen and Edgar, 1985; Levi-Montalcini, 1987). Administration of NGF prevents the prenatal death of sensory neurons (Hamburger and Yip, 1981 ) and the prenatal/postnatal death of sympathetic neurons (Hendry and Campbell, 1976). Similarly, prenatal administration of antiserum of NGF will drastically reduce the number of neurons in sympathetic and sensory ganglia (Gorin and Johnson, 1979; Johnson et al., 1980), including the trigeminal ganglia
(Sikich et al., 1986). NGF also appears to regulate the differentiation of neuronal phenotypes such as transmitter synthesis (Kessler et al., 1983; Kessler, 1985) and action potential duration (Chalazonitis et al., 1987). Trigeminal neurons that project to the iris (Kessler et al., 1983; Kessler, 1985) and the cerebral blood vessels (Schon et al., 1985) synthesize increased levels of neuropeptides in response to SCG lesions. The mechanism responsible for this appears to be a loss of competition from the SCG neurites for a constant source (Shelton and Reichardt, 1986) of NGF produced by the target tissue. Consistent with this is the finding that $40-50 \%$ of trigeminal neurons express NGF receptors in the adult (Richardson et al., 1986). Although it has been suggested that NGF does not influence the survival of the majority of sensory cells postnatally (Gorin and Johnson, 1979; Johnson et al., 1980), Yip et al. (1984) have demonstrated that as many as $20 \%$ of lumbar sensory neurons are still dependent on NGF in the neonate. Thus, artery innervating trigeminal cells may still be dependent postnatally on NGF for survival as well as for differentiation. In sympathetically lesioned neonates NGF availability may actually decrease (if intracranial vessel maturation itself is inhibited), resulting in increased cell death. Alternatively, if trigeminal-MCA cells are dependent on other molecules (see below), then any putative increase in NGF availability after SCG lesions would not prevent the death of trigeminal cells innervating the MCA.

Recently, factors in addition to NGF have been shown to promote the survival and neurite extension of trigeminal cells in culture (Lumsden and Davies, 1983; Davies et al., 1986). Survival factors from 2 potential targets, muscle (skeletal muscle factor) and CNS (brain-derived neurotrophic factor), are additive in promoting the survival of trigeminal mesencephalic neurons in culture (Davies et al., 1986). These results suggest that trigeminal cells with access to the proper central and peripheral targets have a competitive advantage for survival. However, it is important to note that excess of survival factor from either target alone will promote the survival of these neurons in culture (Davies et al., 1986). We have suggested that a trigeminal neuron is at a competitive advantage if it has an extensively collateralized innervation of its cerebral artery target or projections to other targets (O'Connor and van der Kooy, 1986b). Possibly an arterial (or a more general "visceral") target factor exists, the presence of which promotes the survival, and possibly the transmitter differentiation (O'Connor and van der Kooy, 1988), of specifically the artery projecting trigeminal cells. This factor may be the limiting factor for the survival of trigeminal-MCA neurons that do not have axon collaterals to the forehead.

\section{Mechanisms of interaction between sympathetic and trigeminal neurons}

Direct interaction. There are 2 different mechanisms whereby an intact SCG projection could influence the availability of putative survival factors. First, the SCG projection may have a direct afferent effect on trigeminal neurons. Consistent with this, several investigators have shown that the loss of afferent input to motoneurons (Okado and Oppenheim, 1984) and ciliary ganglion cells (Wright, 1981; Furber et al., 1987; Meriney et al., 1987) results in an increased cell loss during the normal cell death period. This afferent effect on motoneurons is independent of target-derived factors, as even with increased peripheral support $20 \%$ of the motoneurons will still die when deafferented (Okado and Oppenheim, 1984). In support of such a direct interaction in our results, a subpopulation of trigeminal sensory 
axons is observed in close anatomical apposition to catecholamingeric SCG axons in the adventitia and periadventitia of cerebral arteries (Matsuyama et al., 1985), and in vitro sensory axons will readily interact with sympathetic neurites (Kapfhammer and Raper, 1987). The SCG neurites may directly promote in vivo trigeminal neuron survival through activity (Devor, 1983; Blumberg and Janig, 1984; Levine et al., 1986) or release of a trophic factor (Richardson and Ebendal, 1982). However, sensory afferents appear to be activated by sympathetic neurites only in abnormal states (Devor, 1983; Blumberg and Janig, 1984); very few sensory afferents are activated by sympathetic neurons under normal physiological conditions (Blumberg and Janig, 1984). In addition, most of the trophic factor present in sympathetic nerves is probably of glial origin (Richardson and Ebendal, 1982; Abrahamson et al., 1986), so that sympathetic trophic effects may be mediated by way of Schwann cells.

Indirect interaction. A second possible way for SCG neurons to promote trigeminal neuron survival may be through an interaction with their common MCA target. The exact common cellular target that may be responsible for the release of putative survival factors at the MCA is not known. However, a likely candidate is the smooth muscle in the tunica media. Trigeminal and SCG fibers run in the same fascicles in the periadventitia and adventitia of the cerebral arteries, and each fiber type forms terminal-like endings approximately $100 \mathrm{~nm}$ from the outer edge of the smooth muscle layered tunica media (Matsuyama et al., 1985). Thus, these smooth muscle cells may be an important source of survival factors that act on the trigeminal or sympathetic cells. The SCG projection may be necessary for the complete maturation or maintenance of the MCA target. As mentioned in the introduction, much of the development of the sympathetic innervation of the vasculature takes place postnatally in the rat (Ljung and Stage, 1975; Cowen and Burnstock, 1986). The functional interaction of sympathetic nerves with the vasculature is necessary for the normal development of the smooth muscles in the vessel walls (Bevan, 1975; Bevan and Bevan, 1981; Bevan and Tsuru, 1981; Smith, 1986). Early postnatal SCG lesions (P28) in the rabbit lead to the arrest of the development of the central ear artery. Fewer vascular smooth muscle cells divide in sympathetically denervated ear arteries, resulting in a thinner media layer (Bevan, 1975; Bevan and Bevan, 1981; Bevan and Tsuru, 1981). Indeed, adrenergic activity appears to be a stimulus for smooth muscle cells to divide (in vivo and in vitro; Bevan and Bevan, 1981; Bevan and Tsuru, 1981; Blaes and Boissel, 1983). Trigeminal axons course predominantly along the media-adventitial border in the MCA wall (Matsuyama et al., 1985), and thus the smooth muscle may be an important source of survival factors. In the present study, the development of the MCA may have been arrested by the loss of sympathetic activity at the MCA target, resulting in an underdeveloped target and subsequently less production of a target-derived survival factor. However, the cerebral vessels in the SCG lesioned rats were not macroscopically different from those in control rats, and lesioned vessels still supported a full adult complement of trigeminal projections. Thus, direct sympathetic activity may not be necessary for target development but rather may be necessary for the release of survival factors from the MCA target. In support of the above speculations, and in contrast to the increased survival of motoneurons after skeletal neuromuscular blockade, there may be a small increase in the death of autonomic neurons after autonomic neuromuscular activity blockade (Meriney et al., 1987).

\section{Other loci of interaction}

The above model and discussion assume that the locus of the SCG lesion effect is the intracranial arteries. We make this assumption for the following reasons. First, the SCG and the trigeminal ganglion cells both project to the MCA (and other intracranial arteries), and both the sympathetic projection and the sensory projection exhibit early postnatal cell death ( $\mathrm{O}^{\prime} \mathrm{Con}-$ nor and van der Kooy, 1986b; present report). Second, these 2 projections normally compete with one another along the arteries for NGF in adult rats (Schon et al., 1985). Third, lesions of the SCG do not appear to affect the trigeminal ganglion as a whole nor the number of forehead projecting cells specifically. However, other loci for the SCG lesion effect must be considered.

First, the cell bodies of the trigeminal neurons projecting to the MCA may be affected directly by the SCG lesion. For example, the lesion may produce a detrimental systemic effect, resulting in the death of many trigeminal cells throughout the ganglion. However, this explanation is untenable given that the number of trigeminal cells with forehead projections does not appear to differ between SCG lesioned and control rats. Alternatively, the SCG lesions may remove sympathetic fibers that may normally interact selectively with MCA projecting trigeminal perikarya in the ganglion. Although no synapses have been observed in the trigeminal ganglion (Pineda et al., 1967), a local paracrine effect is possible, as sympathetic nerves have been proposed to course through the trigeminal ganglion (Schon et al., 1986). An SCG lesion effect on specific trigeminal perikarya could explain the protracted cell death observed in SCG lesioned animals (over a time when trigeminal cells that are going to die no longer project to the MCA). This putative paracrine lesion effect implies that only the MCA projecting trigeminal neurons have receptors on their cell bodies for a released sympathetic factor. Thus, this scenario moves the locus of the lesion action to a site where there is little evidence of an anatomical interaction between the SCG and the trigeminal cell bodies that project to the MCA.

A second alternative locus of action of the lesion may be responsible for maintenance of trigeminal cells with collaterals to the forehead and MCA. An SCG lesion may decrease competitive effects in the forehead and thus allow the maintenance of forehead axon collaterals of trigeminal cells that also project to the MCA. The persistence of the collaterals could be due to the lesion-induced increase in availability of a growth factor such as NGF, an increase that has been observed at other targets receiving both sympathetic and trigeminal projections (Kessler et al., 1983). If in control rats the trigeminal neurons that project to both the MCA and the forehead each retract their forehead axon collateral during development (rather than their MCA collateral), then SCG lesions may promote the maintenance of normally retracted forehead axons. Although we have shown that the number of trigeminal neurons projecting to the forehead does not change significantly in the postnatal period (O'Connor and van der Kooy, 1986b), the small number of forehead axons that may retract under normal conditions and persist in the lesioned animals might be too small to detect among the large population or trigeminal cells that project only to the forehead. However, invoking lesion effects in the forehead would mean that 2 separate loci of action would be required to explain the increased trigeminal cell death and maintenance of forehead collaterals after neonatal SCG lesions. The model presented 
above seems more parsimonious in that only a single intracranial artery locus of action of the SCG lesion is required to explain the selective survival of only trigeminal cells with collaterals to the MCA and forehead.

In conclusion, our results appear to contradict a model in which heterospecific competition between 2 neuronal pools determines their survival. The results support a model postulating cooperation between 2 neuronal pools innervating a common target but competition within each pool. We found that lesions of the SCG at birth do not prevent but rather promote the postnatal cell death of the trigeminal projection to the MCA. The SCG normally cooperates to promote the survival of trigeminal-MCA projections, and thus lesions of the SCG may result in a more stringent homospecific competition for survival among the cells in this trigeminal projection. Thus, as observed, more trigeminal neurons die in the neonatally sympathectomized animals, and only those cells with a distinct competitive advantage survive. We propose that axon collaterals to more than 1 target may provide that competitive advantage.

\section{References}

Abercrombie, M. (1946) Estimation of nuclear population from microtome sections. Anat. Rec. 94: 239-247.

Abrahamson, I. K., P. A. Wilson, and R. A. Rush (1986) Production and transport of endogenous trophic activity in a peripheral nerve following target removal. Brain Res. 27: 117-126.

Andres, K. H., M. von During, K. Muszynski, and R. F. Schmidt (1987) Nerve fibres and their terminals of the dura mater encephali of the rat. Anat. Fmbryol. 175:289-301

Bennet, M. R., and N. A. Lavidis (1982) Development of the topographical projection of motor neurons to amphibian muscle accompanies motor neuron death. Dev. Brain Res. 2: 448-452.

Berg, D. K. (1982) Cell death in neuronal development. In Neuronal Development, N. C. Spitzer, ed., pp. 297-324, Plenum, New York.

Bevan, J. A., and R. D. Bevan (1981) Developmental influences on vascular structure and function. In Development of the Autonomic Nervous System, I. K. Elliot and G. Lawrenson, eds., pp. 94-107, Ciba Foundation Symposium 83, Pitman, London.

Bevan. R. D. (1975) Effect of sympathetic denervation on smooth muscle cell proliferation in the growing rabbit ear artery. Circulation Res. 37: 14-19.

Bevan, R. D., and H. Tsuru (1981) Long-term influence of the sympathetic nervous system on arterial structure and reactivity: Possible factor in hypertension. In Disturbances in Neurogenic Control of the Circulation, F. M. Abboud, H. A. Fozzard, J. P. Gilmore, and D. J. Reis, eds., pp. 153-160, American Physiological Society, Bethesda, MD.

Blaes, N., and J.-P. Boissel (1983) Growth-stimulating effect of catecholamines on rat aortic smooth muscle cells in culture. J. Cell. Phys. 116: 167-172.

Blumberg, H., and W. Janig (1984) Discharge pattern of afferent fibers from a neuroma. Pain 20: 335-354.

Brown, M. C., and C. M. Booth (1y83) Postnatal development of the adult pattern of motor axon distribution in rat muscle. Nature 304 : 741-742.

Caminiti, R.. and G. M. Innocenti (1981) The postnatal development of somatosensory callosal connections after partial lesions of somatosensory areas. Exp. Brain Res. 42: 53-62.

Chalazonitis, A., E. R. Peterson, and S. M. Crain (1987) Nerve growth factor regulates the action potential duration of mature sensory neurons. Proc. Natl. Acad. Sci. USA 84: 289-293.

Cowan, W. M., and E. Wenger (1967) Cell loss in the trochlear nucleus of the chick during normal development and after radical extirpation of the optic vesicle. J. Exp. Zool. 164: 265-280.

Cowan, W. M., J. W. Fawcett, D. D. M. O'Leary, and B. B. Stanfield (1984) Regressive events in neurogenesis. Science 225: 1258-1265.

Cowen, T., and G. Burnstock (1986) Development, aging, and plasticity of perivascular autonomic nerves. In Developmental Neurobiology of the Autonomic Nervous System, P. M. Gootman, ed., pp. 211-232, Humana, Clifton, NJ.
Cowen, T., C. Alafaci, H. A. Crockard, and G. Burnstock (1986) 5-HT-Containing nerves to major cerebral arteries of the gerbil originate in the superior cervical ganglia. Brain Res. 384: 51-59.

Cowen, T., C. Alafaci, H. A. Crockard, and G. Burnstock (1987) Origin and postnatal development of nerves showing 5-hydroxytryptaminelike immunoreactivity supplying major cerebral arteries of the rat. Neurosci. Lett. 78: 121-126.

Crepel, F. (1982) Regression of functional synapses in the immature mammalian cerebellum. Trends Neurosci. 5: 266-269.

Crepel, F., J. Mariani, and N. Delhaye-Bouchaud (1976) Evidence for a multiple innervation of Purkinje cells by climbing fibers in the immature rat cerebellum. J. Neurobiol. 7: 567-578.

Cunningham, T. J. (1982) Naturally occurring neuron death and its regulation by developing neural pathways. Int. Rev. Cytol. 74: 163186.

Davies, A., and A. Lumsden (1984) Relation of target encounter and neuronal death to nerve growth factor responsiveness in the developing mouse trigeminal ganglion. J. Comp. Neurol. 223: 124-137.

Davies, A. M., H. Thoenen, and Y.-A. Barde (1986) Different factors from the central nervous system and periphery regulate the survival of sensory neurones. Nature 319: 497-499.

Devor, M. (1983) Nerve pathophysiology and mechanisms of pain in causalgia. J. Aut. Nerv. Sys. 7: 371-384.

Ebendal, T., L. Olson, A. Seiger, and K.-O. Hedlund (1980) Nerve growth factors in the rat iris. Nature 286: 25-28.

Erzurumlu, R. S., and H. P. Killackey (1983) Development of order in the rat trigeminal system. J. Comp. Neurol. 213: 365-380.

Forbes, D. J., and C. Welt (1981) Neurogenesis in the trigeminal ganglion of the albino rat: A quantitative autoradiographic study. $J$. Comp. Neurol. 199: 133-147.

Furber, S., R. W. Oppenheim, and D. K. Prevette (1987) Naturallyoccurring neuron death in the ciliary ganglion of the chick embryo following removal of preganglionic input: Evidence for the role of afferents in ganglion cell survival. J. Neurosci. 7: 1816-1832.

Gorin, P. D., and E. M. Johnson, Jr. (1979) Experimental autoimmune model of nerve growth factor deprivation: Effect on developing periphcral sympathetic and sensory neurons. Proc. Natl. Acad. Sci. USA 76: $5382-5386$.

Hamburger, V., and R. Levi-Montalcini (1949) Proliferation, differentiation and degeneration in the spinal ganglia of the chick embryo under normal and experimental conditions. J. Exp. Zool. 111: 457502.

Hamburger, V., and R. W. Oppenheim (1982) Naturally occurring neuronal death in vertebrates. Neurosci. Comm. 1: 39-55.

Hamburger, V., and J. W. Yip (1984) Reduction of experimentally induced neuronal death in spinal ganglia of the chick embryo by nerve growth factor. J. Neurosci. 4: 767-774.

Hanko, J., J. E. Hardebo, J. Kahrstrom, C. Owman, and F. Sundler (1985) Calcitonin gene-related peptide is present in mammalian cerebrovascular nerve fibres and dilates pial and peripheral arteries. Neurosci. Lett. 57: 91-95.

Hendry, I. A. (1977) Cell division in the developing sympathetic nervous system. J. Neurocytol. 6: 299-309.

Hendry, I. A., and J. Campbell (1976) Morphometric analysis of rat superior cervical ganglion after axotomy and nerve growth factor treatment. J. Neurocytol. 5: 351-360.

Herrup, K., and K. Sunter (1987) Numerical matching during cerebellar development: Quantitative analysis of granule cell death in staggerer mouse chimeras. J. Neurosci. 7: 829-836.

Hollyday, M., and V. Hamburger (1976) Reduction of the naturally occurring motor neuron loss by enlargement of the periphery. J. Comp. Neurol. 170: 311-320.

Johnson, E. M., Jr., P. D. Gorin, L. B. Brandeis, and J. P. Pearson (1980) Dorsal root ganglion neurons are destroyed by exposure in utero to maternal antibody to ncrve growth factor. Science 210:916918.

Kapfhammer, J. P., and J. A. Raper (1987) Interactions between growth cones and neurites growing from different neural tissues in culture. $J$. Neurosci. 7: 1595-1600.

Kessler, J. A. (1985) Parasympathetic, sympathetic and sensory interactions in the iris: Nerve growth factor regulates cholinergic ciliary ganglion innervation in vivo. J. Neurosci. 5: 2719-2725.

Kessler, J. A., W. O. Bell, and I. B. Black (1983) Interactions between the sympathetic and sensory innervation of the iris. J. Neurosci. 3 : 1301-1307. 
Korshing, S., and H. Thuenerl (1985) Treatment with 6-hydroxydopamine and colchicine decreases nerve growth factor levels in sympathetic ganglia and increases them in the corresponding target tissues. J. Neurosci. 5: 1058-1061.

Lance-Jones, C., and L. Landmesser (1980) Motoneurone projection patterns in embryonic chick limbs following partial deletions of the spinal cord. J. Physiol. (Lond.) 302: 559-580.

Lanser, M. E., J. L. Carrington, and J. F. Fallon (1986) Survival of motoneurons in the brachial lateral motor column of limbless mutant chick embryos depends on the periphery. J. Neurosci. 6: 2551-2557.

Levi-Montalcini, R. (1987) The nerve growth factor 35 years later. Science 237: 1154-1162.

Levine, J. D., Y. O. Taiwo, S. D. Collins, and J. K. Tam (1986) Nonadrenaline hyperalgesia is mediated through interaction with sympathetic postganglionic neurone terminals rather than activation of primary afferent nociceptors. Nature 323: 158-160.

Ljung, B., and D. Stage (McMurphy) (1975) Postnatal ontogenetic development of neurogenic and myogenic control in the rat portal vein. Acta Physiol. Scand. 94: 112-127.

Lumsden, A. G. S., and A. M. Davies (1983) Earliest sensory nerve fibres are guided to peripheral targets by attractants other than nerve growth factor. Nature 306: 786-788.

Lund, R. D., F.-L. F. Chang, and P. W. Land (1984) The development of callosal projections in normal and one eyed rats. Dev. Brain Res. 14: 139-142.

Matsuyama, T., S. Shiosaka, A. Wanaka, S. Yoneda, K. Kimura, T. Hayakawa, P. C. Emson, and M. Tohyama (1985) Fine structure of peptidergic and catecholaminergic nerve fibers in the anterior cerebral artery and their interrelationship: An immunoclectron microscopic study. J. Comp. Neurol. 235: 268-276.

Mayberg, M. R., N. T. Zervas, and M. A. Moskowitz (1984) Trigeminal projections to supratentorial pial and dural blood vessels in cats demonstrated by horseradish peroxidase histochemistry. J. Comp. Neurol. 223: 46-56.

Meriney, S. D., G. Pilar, M. Ogawa, and R. Nunez (1987) Differential neuronal survival in the avian ciliary ganglion after chronic acetylcholine receptor blockade. J. Neurosci. 7: 3840-3849.

O'Connor, T., and D. van der Kooy (1986a) Pattern of intracranial and extracranial projections of trigeminal ganglion cells. J. Neurosci. 6: 2200-2207.

O'Connor, T., and D. van der Kooy (1986b) Cell death organizes the postnatal development of the trigeminal innervation of the cerebral vasculature. Dev. Brain Res. 27: 223-233.

O'Connor, T., and D. van der Kooy (1988) Enrichment of a vasoactive neuropeptide (calcitonin gene related peptide) in the trigeminal sensory projection to the intracranial arteries. J. Neurosci. 8: 2468-2476.

Okado, N., and R. W. Oppenheim (1984) Cell death of motoneurons in the chick embryo spinal cord. IX. The loss of motoneurons following removal of afferent inputs. J. Neurosci. 4: 1639-1652.

Oppenheim, R.W. (1981) Neuronal cell death and some related regressive phenomena during neurogenesis: A selective historical review and progress report. In Studies in Developmental Neurobiology. W. M. Cowan, ed., pp. 74-133, Oxford U. P., Oxford, U.K.

Pilar, G., and L. Landmesser (1976) Ultrastructural differences during embryonic cell death in normal and peripherally deprived ciliary ganglia. J. Cell Biol. 68: 339-356.

Pilar, G., L. Landmesser, and L. Burstein (1980) Competition for survival among developing ciliary ganglion cells. J. Neurophysiol. 43: 233-254.
Pineda, A., D. S. Maxwell, and L. Kruger (1967) The fine structure of neurons and satellite cells in the trigeminal ganglion of cat and monkey. Am. J. Anat. 121: 461-488.

Rhoades, R. W., and D. D. Dellacroce (1980) Neonatal enucleation induces an asymmetric pattern of visual callosal connections in hamsters. Brain Res. 202: 189-195.

Richardson, P. M., and T. Ebendal (1982) Nerve growth activities in rat peripheral nerve. Brain Res. 246: 57-64.

Richardson, P. M., V. M. K. Verge Issa, and R. J. Riopelle (1986) Distribution of neuronal receptors for nerve growth factor in the rat. J. Neurosci. 6: 2312-2321.

Rubin, E. (1985) Development of the rat superior cervical ganglion: Ganglion cell maturation. J. Neurosci. 5: 673-684.

Saito, K., L.-Y. Liu-Chen, and M. A. Moskowitz (1987) Substance $P$-like immunoreactivity in rat forebrain leptomeninges and cerebral vessels originates from the trigeminal but not sympathetic ganglia. Brain Res. 403: 66-71

Schon, F., M. Ghatei, J. M. Allen, P. K. Mulderry, J. S. Kelly, and S. R. Bloom (1985) The effect of sympathectomy on calcitonin generelated peptide levels in the rat trigeminovascular system. Brain Res. 348: 197-200.

Shelton, D., and L. F. Reichardt (1986) Studies on the regulation of beta-nerve growth factor gene expression in the rat iris: The level of mRNA-encoding nerve growth factor is increased in irises placed in explant cultures in vitro, but not in irises deprived of sensory or sympathetic innervation in vivo. J. Cell Biol. 102: 1940-1948.

Sikich, L., T. A. Woolsey, and E. M. Johnson, Jr. (1986) Effect of a uniform partial denervation of the periphery on the peripheral and central vibrissal system in guinca pigs. J. Ncurosci. 6: 1227-1240.

Smith, P. G. (1986) Relationships between the sympathetic nervous system and functional development of smooth muscle end organs. In Developmental Neurobiology of the Autonomic Nervous System, P. M. Gootman, ed., pp. 251-278, Humana, Clifton, NJ.

Sohal, G. S., S. D. Stoney, Jr., T. Arumugam, T. Yamashita, and T. S. Knox (1986) Influence of reduced neuron pool on the magnitude of naturally occurring motor neuron death. J. Comp. Neurol. 247: 516528.

Tanaka, H., and L. Landmesser (1986) Cell death of lumbosacral motoneurons in chick, quail, and chick-quail chimera embryos: A test of the quantitative matching hypothesis of neuronal cell death J. Neurosci. 6: 2889-2899.

Thoenen, H., and D. Edgar (1985) Neurotrophic factors. Science 229: 238-242.

Wanaka, A., T. Matsuyama, S. Yoneda, K. Kimura, T. Kamada, S. Girgis, I. MacIntyre, P. C. Emson, and M. Tohyama (1986) Origins and distribution of calcitonin gene-related peptide-containing nerves in the wall of the cerebral arteries of the guinea pig with special reference to the coexistence with substance P. Brain Res. 369: 185192.

Woodward, D. J., B. J. Hoffer, and J. Altman (1974) Physiological and pharmacological properties of Purkinje cells in rat cerebellum degranulated by postnatal X-irradiation. J. Neurobiol. 5: 283-304.

Wright, L. L. (1981) Cell survival in the chick embryo ciliary ganglion is reduced by chronic ganglion hlockade. Dev. Brain Res. 1:283-286.

Yip, H. K., K. M. Rich, P. A. Lampe, and E. M. Johnson, Jr. (1984) The effects of nerve growth factor and its antiserum on the postnatal development and survival after injury of sensory neurons in rat dorsal root ganglia. J. Neurosci. 4: 2986-2992. 